Indonesian Journal of Physics and Nuclear Applications

Volume 1, Number 3, October 2016, p. 128-137

ISSN 2549-046X, (C) FSM UKSW Publication

\title{
Optimization of a Beam Shaping Assembly Design for Boron Neutron Capture Cancer Therapy Facility Based on $30 \mathrm{MeV}$ Cyclotron
}

\author{
I Made Ardana ${ }^{a 1}$, Kusminarto ${ }^{a}$, Yohannes Sardjono ${ }^{b}$ \\ aDepartment of Physics, Faculty of Mathematics and Natural Sciences, Gadjah Mada University \\ - Sekip Utara Bulaksumur, Yogyakarta 55281, Indonesia \\ ${ }^{b}$ PSTA-BATAN, Jln. Babarsari Kotak Pos 6010 ykbb, Yogyakarta 55281, Indonesia
}

\begin{abstract}
A series of simulations has been carried out using a Monte Carlo N Particle X code to find out the final composition and configuration of a neutron Beam Shaping Assembly (BSA) to moderate the fast neutron flux which is generated from the thick disk-type beryllium target. The final configuration for neutron BSA design included 35 $\mathrm{cm}$ lead as reflector, $39 \mathrm{~cm}$ alumina as moderator, $8.2 \mathrm{~cm}$ lithium fluoride as fast neutron filter and $0.5 \mathrm{~cm}$ boron carbide as thermal neutron filter. Bismuth, lead fluoride, and lead were chosen as the aperture, reflector, and gamma shielding, respectively. The disk-type of beryllium target is $19 \mathrm{~cm}$ in diameter with $0.5 \mathrm{~cm}$ thickness which is covered by copper plate to hold the water pressured coolant. A higher yield of neutron production requires a higher intensity of proton beams, which generate much heats and causes the target material to melt. Therefore, it is useful to consider the temperature distribution on the target material with flowing water coolant by means of computer modeling while designing the target. ANSYS-Fluent code will be used to estimate the thermal transfer and heat calculation in a solid target during beam irradiation. Epithermal neutron flux in the suggested design were $1,03 \times 10^{9} \mathrm{n} / \mathrm{cm}^{2} \mathrm{~s}$, with almost all IAEA parameters for BNCT BSA design has been satisfied.
\end{abstract}

Keywords: ANSYS-Fluent, Beam Shaping Assembly, Monte Carlo N Particle-X

\section{INTRODUCTION}

Cancers figure among the leading causes of morbidity and mortality worldwide, with approximately 14 million new cases and 8.2 million cancer related deaths in 2012 (WHO, 2015). A wide variety of therapeutic approaches are used in the management of cancers. Due to the high rate of recurrence of cancers after surgery, radiotherapy and chemotherapy have recently been added as additional treatment strategies, to improve disease control and survival (Aguino et al., 2011). It is important to develop a new cancer therapy method that can be used to overcome some of the previous cancer therapy methods weakness. Currently it has developed a therapy that is expected to deal with previous methods weakness. The cancer treatment method known as (BNCT) (Andoh et al., 2011). Boron Neutron Capture Therapy (BNCT) has been advocated for many decades as an innovative form of radiotherapy that, in principle, has the potential to be the ideal form of treatment for many types of cancers (Moss 2014). The BNCT has been performed using research reactors which are usually located at place far from hospitals. At Kyoto University Research Reactor Institute (KURRI), more than 450 clinical studies of boron neutron capture therapy (BNCT) have been performed using a research reactor as of December 2013 (Tanaka, 2014).

Accelerator based BNCT systems that can be constructed near hospitals are necessary and necessitate low activation of structure materials and more likely possible to developed as cancer treatment facility (Yuka, 2014). To deal with the increasing number of candidates for BNCT, development of an accelerator-based BNCT (AB-BNCT) system is a prerequisite (Suzuki, 2009). A new Cyclotron-Based Epithermal Neutron Source (C-BENS) was installed at

${ }^{1}$ Corresponding author. Email: i.made.ardana@mail.ugm.ac.id 


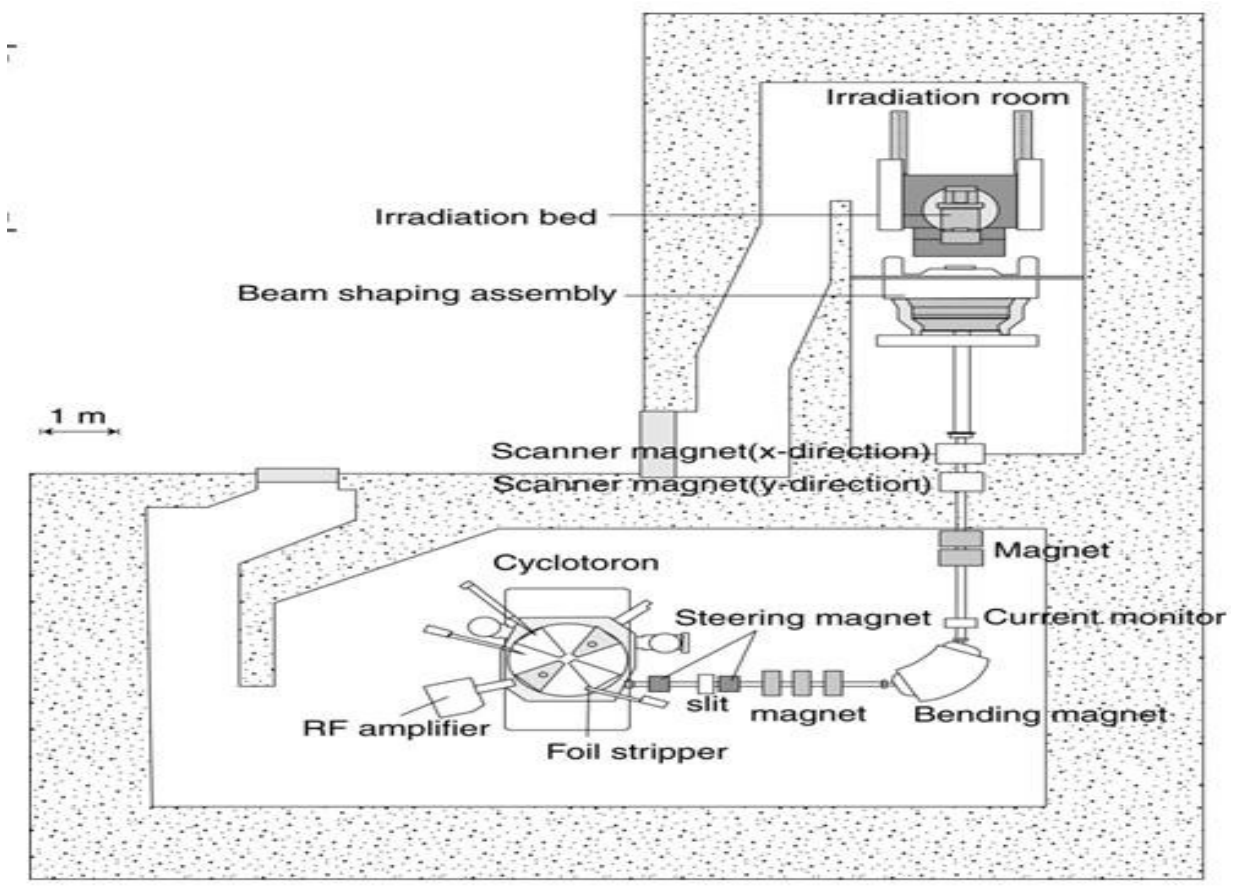

Figure 1. Layout of the cyclotron BNCT system at KURRI

Kyoto University Research Reactor Institute in December 2008. It was confirmed that the intensity of the epithermal neutron beam was about $1 \times 10^{9} \mathrm{~cm}^{-2} \mathrm{~s}^{-1}$ which could be used for clinical trial of BNCT (Imoto, 2011). The facility layout is shown in Fig. 1. It is composed of a HM-30 cyclotron, a beam transport system, an irradiation and treatment system with auxiliary systems (Mitsumoto, 2010).

The accelerators as a neutron source for BNCT have been studied actively over the decade. Its motivation is derived from their advantages over the reactor-based systems. In epi-thermal neutron irradiation fields for BNCT, the neutron energy spans over a wide (Ueda, 2015). In that cases, majority of the produced neutrons are fast neutrons $(10 \mathrm{keV})$, and several types of moderators to be combined has been proposed to obtain thermal ( $\sim 0.5$ $\mathrm{eV})$ and epithermal $(0.5 \mathrm{eV}-10 \mathrm{keV})$ neutrons. Also, gamma rays and fast neutrons are reduced with the moderator assembly, consisting of moderator, reflector, collimator, gamma rays shield, etc (Tanaka, 2014).
In BNCT method, it is needed a neutron source which is produced neutron flux that is suitable for BNCT system. BNCT neutron flux may be produced from a neutron Beam Shaping Assembly (BSA) design. BSA is a system tool that is used to produce the neutron flux corresponding to the flux of neutrons for BNCT therapy (Rasouli and Masoudi, 2012; Faghihi and Khalili, 2013). Neutron which is produced from neutron source generally has a high energy (fast neutron). A moderation system is needed to produce the neutron flux corresponding to the flux of BNCT (epithermal neutrons). A BSA can be composed of several parts including the moderator, reflector, aperture, gamma shielding and thermal neutron filter (Burlon et al., 2011; Pazirandeh et al., 2011; Rasouli and Masoudi, 2012).

Neutron BSA design based on $30 \mathrm{MeV}$ cyclotron for Boron Neutron Capture Therapy (BNCT) facility had been studied before. The study has met all of IAEA parameters for BNCT BSA design. On those simulation calculation shown that the collimator design 


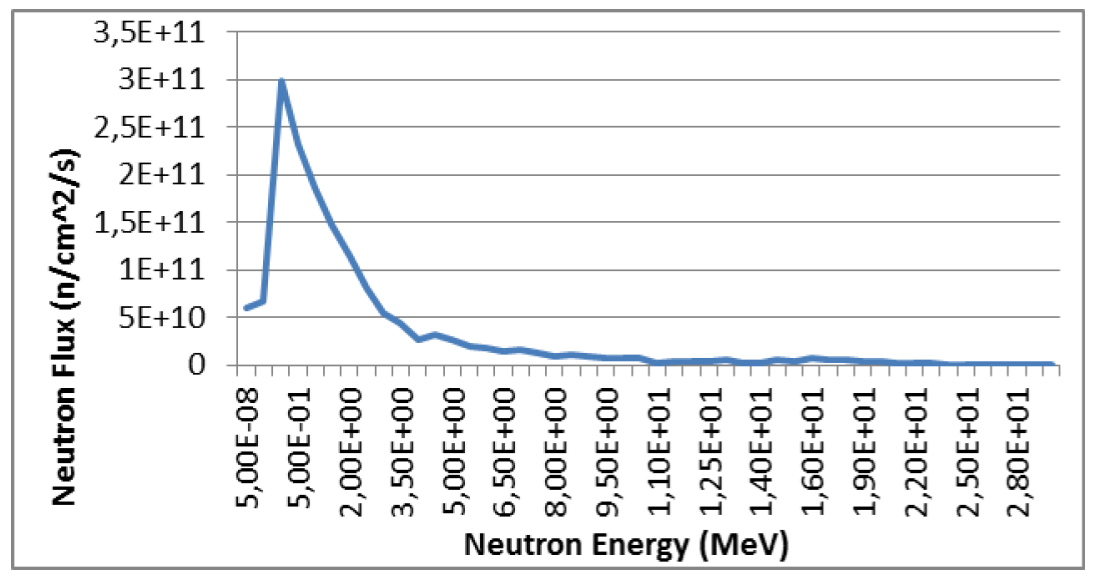

Figure 2. Neutron spectrum produced from ${ }^{9} \mathrm{Be}(\mathrm{p}, \mathrm{n}){ }^{9} \mathrm{~B}$ reaction (Ardana, 2015)

produces $1.33 \times 10^{11}$ total neutron flux on 19 $\mathrm{cm}$ target diameter with $0.5 \mathrm{~cm}$ thickness. The total neutron flux consists of $9.15 \times 10^{7}$ thermal neutron flux, $1.05 \times 10^{10}$ epithermal neutron flux, and $1.23 \times 10^{11}$ fast neutron flux wich is shown on Figure 1.2 as a neutron spectrum. The total neutron flux had been moderated in the designed BSA to produce neutron flux which is suitable for BNCT system (Ardana, 2015). But, these work has not completed ye. The cooling system hasn't designed and target temperature was not calculated. So, it is needed to develop a simulation research in wich including the cooling system design and target temperature calculation.

\section{MATERIALS AND METHODS}

Various simulation were performed in neutron beam shaping assembly design and its simulations in dose evaluation for some types of cancer (Tanaka et al., 2011; Herrera, 2013; Wang et al., 2011; Yonai et al., 2004; Andoh et al., 2011; Capoulat et al., 2014). This study involves two main objectives. First purpose is to find out the most easily obtained moderator and reflector materials. Alumina and lead are used as moderator and reflector material respectively. The second goal is to completing the BSA design with cooling system in which water pressured selected as the coolant. Water selected as the coolant on this study besides it can be used as a coolant it also can be used as a neutron moderator.

To find out the BSA design, we simulated each part of the BSA configuration. Reflector, the best material for a reflector layer should have a high scattering cross section with the fast neutrons to scatter all neutron those produced by ${ }^{9} \mathrm{Be}(\mathrm{p}, \mathrm{n}){ }^{9} \mathrm{~B}$ reaction back into the moderator layer in order to produce the epi-thermal neutrons. Various reflector thickness were simulated to carry out the best reflector configuration. Moderator, a good moderator should have a high scattering cross section for fast neutrons and low absorption cross section for epithermal neutrons. Another parameter is the selection of appropriate materials with an appropriate mass number (IAEA, 2001). Various moderator thickness were simulated to carry out the best moderator material. Various neutron filter and gamma shielding thickness were simulated to carry out the best BSA configuration in which can produced neutron flux that is suitable for BNCT. Collimator, collimator is a part of BSA which is located at the end of the neutron beam exit. Conical shape of the aperture created at the end to concentrate the radiation beam toward the target phantom (Faghihi and Khalili, 2013).

It has been simulated the BSA design including water cooling system using MCNPX code. The simulation focused on the additional 


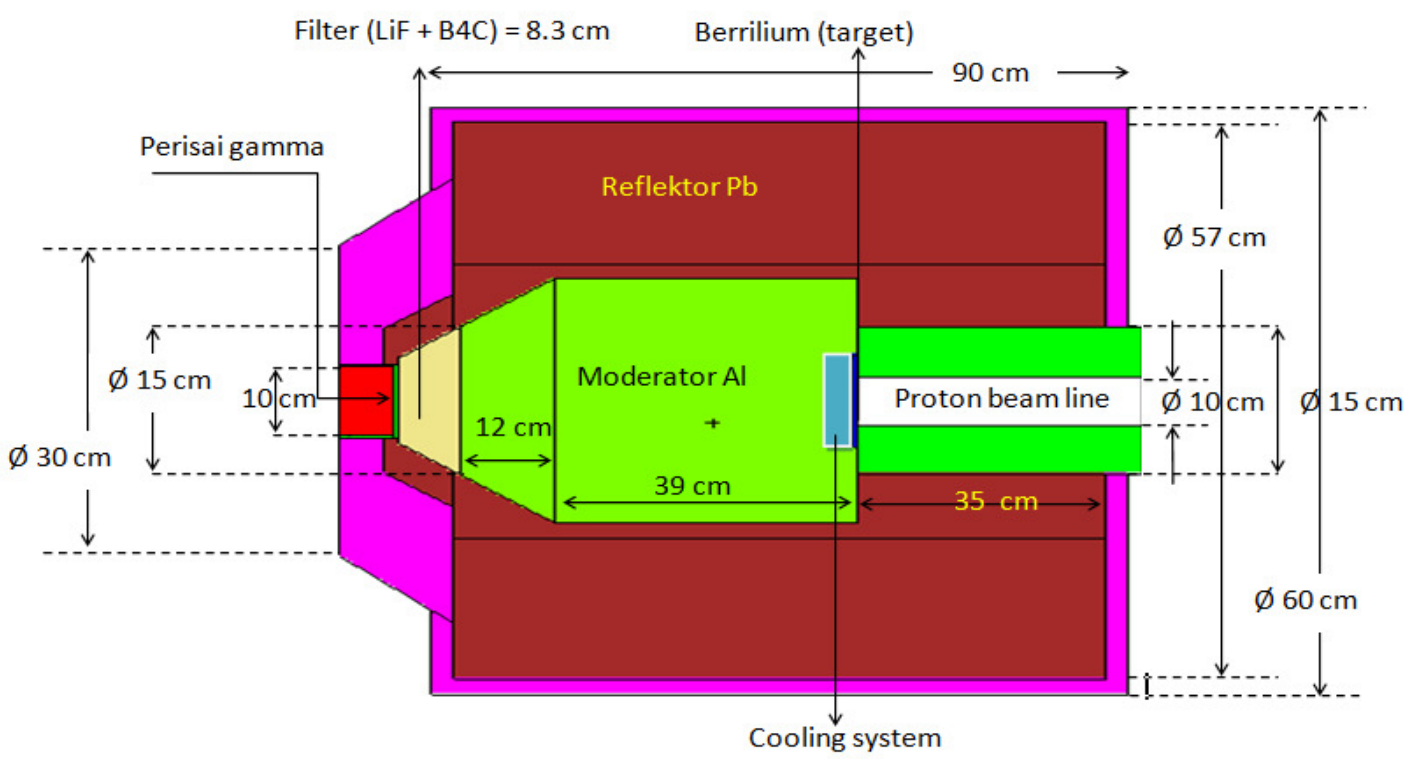

Figure 3. BSA configuration including cooling system

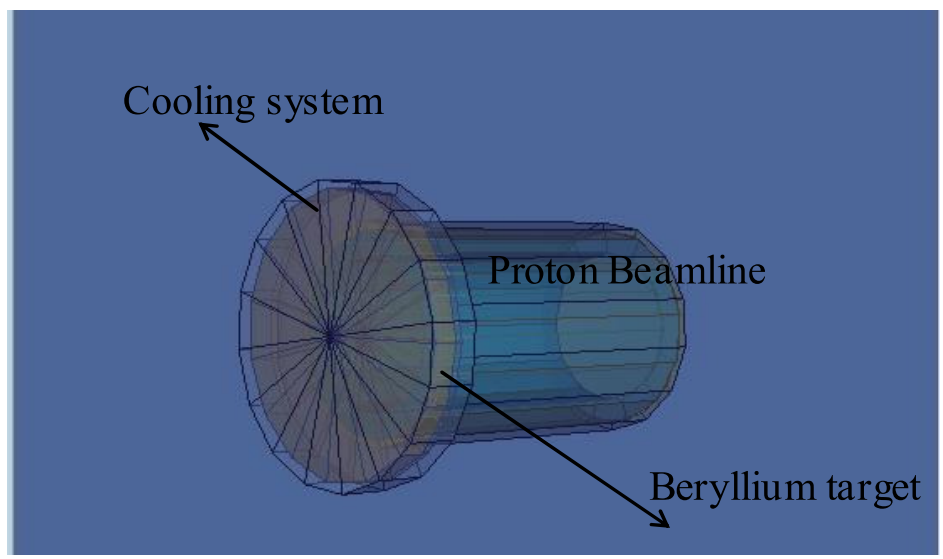

Figure 4. Beryllium target with water cooling system

water cooling system to the last BSA design to find the final BSA design. Often the maximum neutron yield will be limited (at least theoretically) by the maximum power that may be dissipated in the beryllium target. Obviously there are media that can easily be cooled (liquids, in particular water), whereas others need auxiliary cooling media for the heat removal (Drosg, 2011). In this study, we used water pressured water as a coolant that is covered by copper plate as a holder. A precise analysis of neutron transport through BSA has been performed by MCNPX code. The general view of the collimator configuration is shown in Figure 3.
To calculate the neutron flux and neutron dose parameter we use f4:n tally type, f4:p tally type to calculate the gamma dose, and fl:n tally type to calculate the neutron current passing through a surface. From the tallies calculation we can find out the neutron flux characteristic which is produced by designed BSA. After that, we compare the neutron flux characteristic (from designed BSA) with the IAEA neutron flux parameter which is suitable for BNCT system.

Figure 4. shown $3 \mathrm{D}$ view of the water cooling system design. It is used $5 \mathrm{~mm}$ of a copper plate as the water pressured cover to cooling the Beryllium target. Cooling water 
will be forced at a high velocity of $2 \mathrm{~m} / \mathrm{sec}$ and calculated using Ansys-Fluent code.

\section{RESULTS AND DISCUSSION}

${ }^{9} \mathrm{Be}$ was choosen as the target material on this study. ${ }^{9} \mathrm{Be}$ is able to produce greatest neutron flux when compared to the neutron flux generated by other materials like ${ }^{7} \mathrm{Li},{ }^{181} \mathrm{Ta}$ and ${ }^{184} \mathrm{~W}$. Additionally, It has a higher melting and boiling point than ${ }^{7} \mathrm{Li}$ (Ono, 2013). Table 1 shows the target materials characteristics for ${ }^{9} \mathrm{Be},{ }^{7} \mathrm{Li},{ }^{181} \mathrm{Ta}$ and ${ }^{184} \mathrm{~W}$.

A series of simulation were studied to find out the optimal beryllium target thickness in which it can provides the greatest neutron flux. The simulation results are shown on the Figure 5.

Figure 5 shown that the most neutron flux produced when the beryllium target reach $5 \mathrm{~mm}$ in thickness. After $5 \mathrm{~mm}$ beryllium thickness the neutron flux decreasing smoothly. So, the 5 $\mathrm{mm}$ of beryllium was selected as the material target thickness in this study.

To find out the neutron flux distribution, it is simulated the neutron flux angular distribution. The simulations were carried out by meshing the geometry into several angles. The results of this simulation were shown on the Figure 6.

From the Figure 6 it can be seen that the neutron flux more in line with the enlargement of the scattering angles. This suggests that the neutron flux generated on the target system does not lead directly assigned to the aperture. For this condition, we need a reflector to direct the neutron flux into the moderation room. Lead was selected as the reflector material in that it is easier to be obtained than other reflector materials. The lead reflector simulation results shown on the Figure 7.

Table 1 Target materials characteristicsas neutron sources

\begin{tabular}{cccccc}
\hline Target & $\begin{array}{c}\text { Melting point } \\
\left({ }^{0} \mathrm{C}\right)\end{array}$ & $\begin{array}{c}\text { Boiling point } \\
\left({ }^{0} \mathrm{C}\right)\end{array}$ & $\begin{array}{c}\text { Thermal conductivity } \\
(\mathrm{W} / \mathrm{mK})\end{array}$ & $\begin{array}{c}\text { Neutron yield } \\
(\mathrm{n} / \mathrm{s} / \mathrm{mA})\end{array}$ & $\begin{array}{c}\text { Gamma ray per } \\
\text { one neutron }\end{array}$ \\
\hline $\mathrm{Li}$ & 180 & 1340 & 84.7 & $1.14 \times 10^{14}$ & 0.09 \\
$\mathrm{Be}$ & 1278 & 2970 & 201 & $1.90 \times 10^{14}$ & 0.02 \\
$\mathrm{Ta}$ & 3017 & 5448 & 57.5 & $1.27 \times 10^{14}$ & 0.93 \\
$\mathrm{~W}$ & 3422 & 5555 & 174 & $9.65 \times 10^{14}$ & 1.40 \\
\hline
\end{tabular}

Source: Ono, 2013 (Microsoft Power Point Presentation)

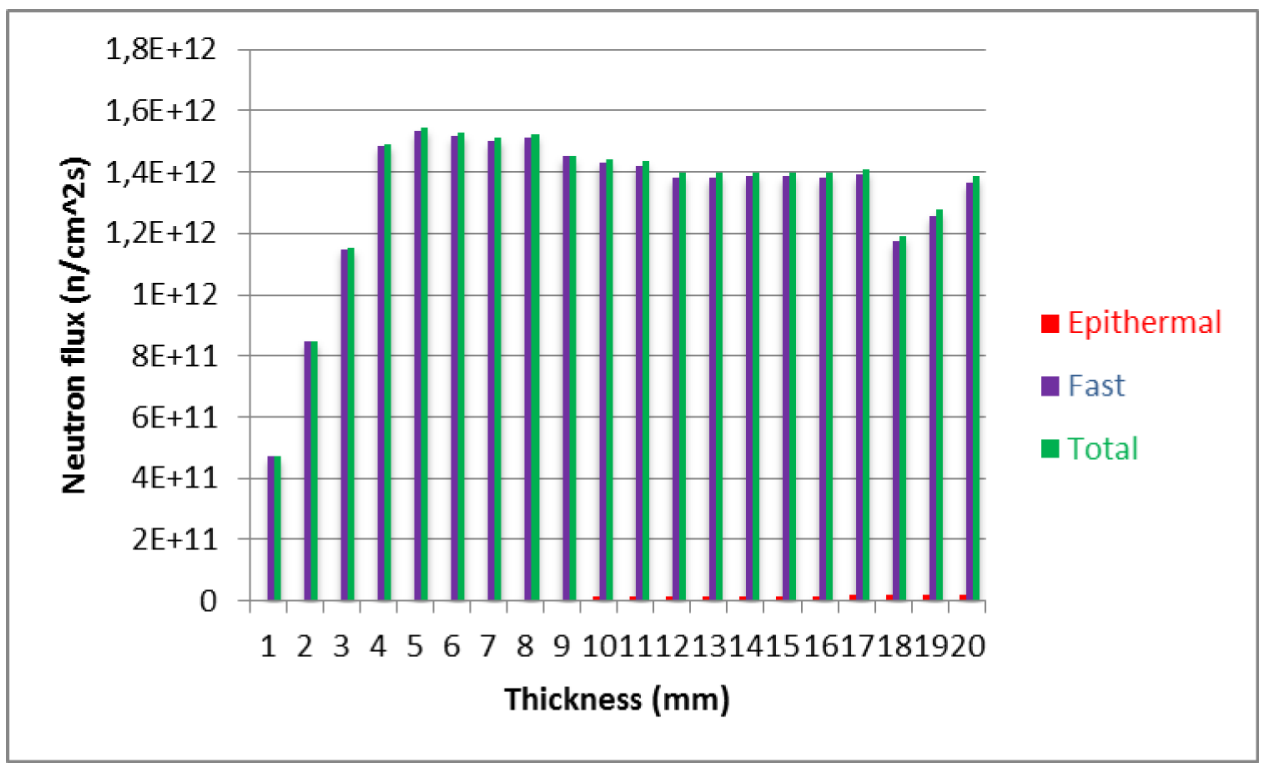

Figure 5. Neutron flux produced by various beryllium target thickness 


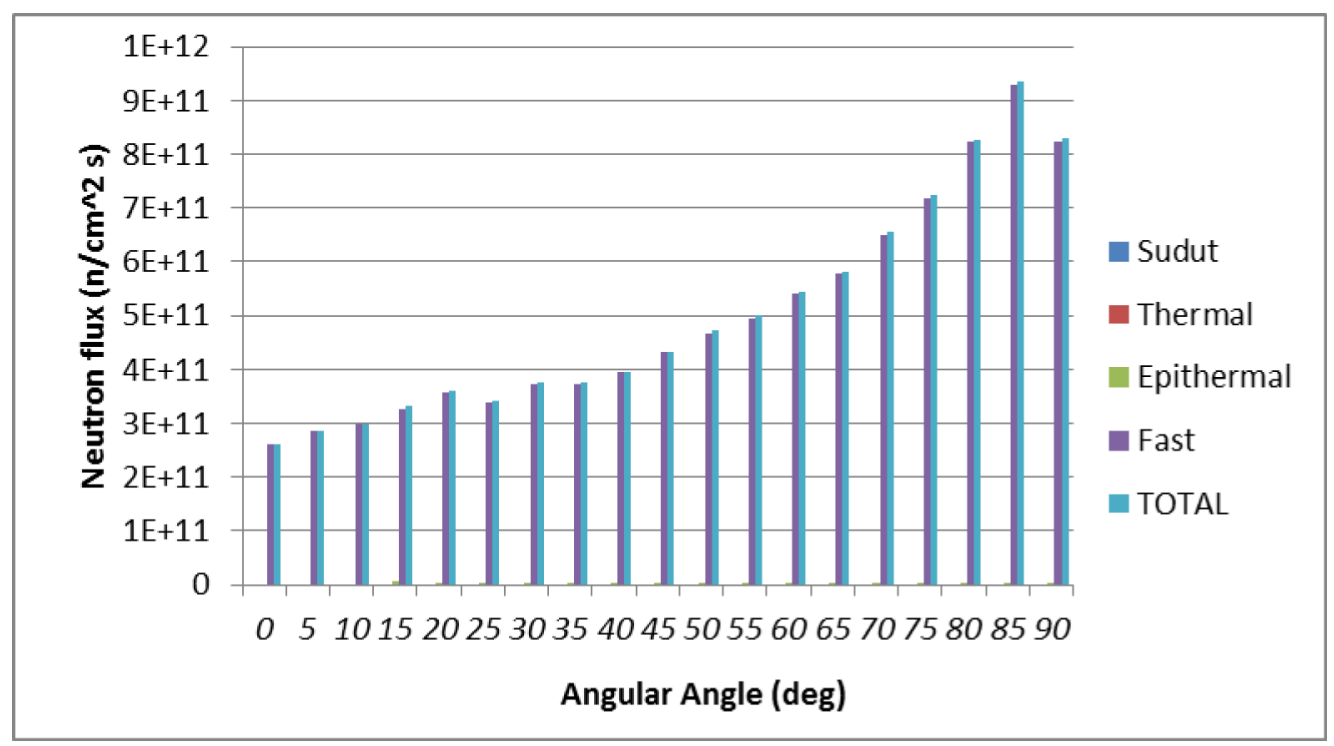

Figure 6. Neutron flux angular distribution from beryllium target

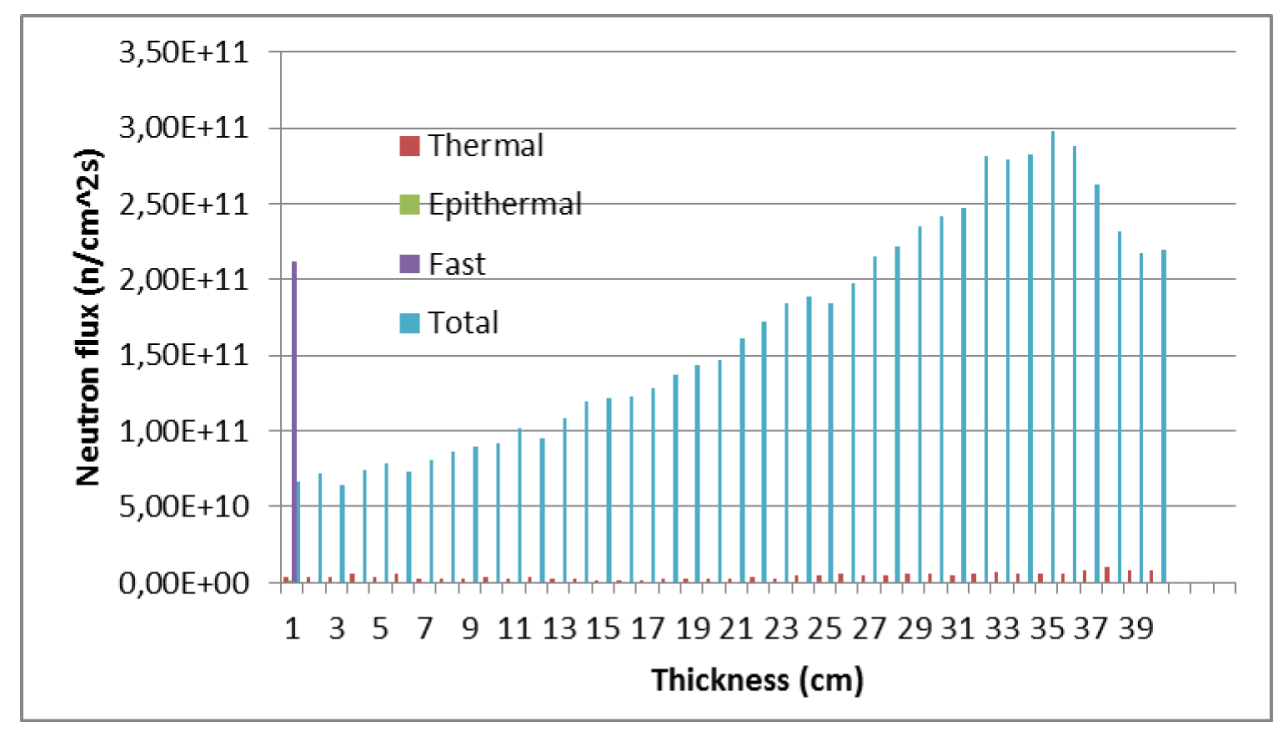

Figure 7. Neutron flux on various lead reflector thickness

Various thickness lead materials were simulated as reflector material thickness in this study. Its output is given in Figure 7. Based on Figure 7, $35 \mathrm{~cm}$ lead thickness is the best thickness lead material to choosen as the reflector parameter because it can maintain the highest neutron flux.

Studies continued to find out the optimal alumina thickness as a moderator. The simulation results shown on Figure 8.

According to the results shown in Fig. 8 , the best moderator material thickness is 39 $\mathrm{cm}$ of alumina. It can generated the highest epithermal neutron flux with low fast neutron contamination. So the $39 \mathrm{~cm}$ alumina has selected as the moderator thickness material on this study. The study was continued in several simulation to findout the optimal neutron filter and gamma shielding materials. $8.5 \mathrm{~cm} \mathrm{LiF}, 0.3$ $\mathrm{cm} \mathrm{B}_{4} \mathrm{C}$, and $0.5 \mathrm{~cm} \mathrm{~Pb}$ were choosen as fast neutron filter, thermal neutron filter, and gamma shielding respectively.

The final neutron BSA design based on 30 $\mathrm{MeV}$ cyclotron has been studied and shown on 


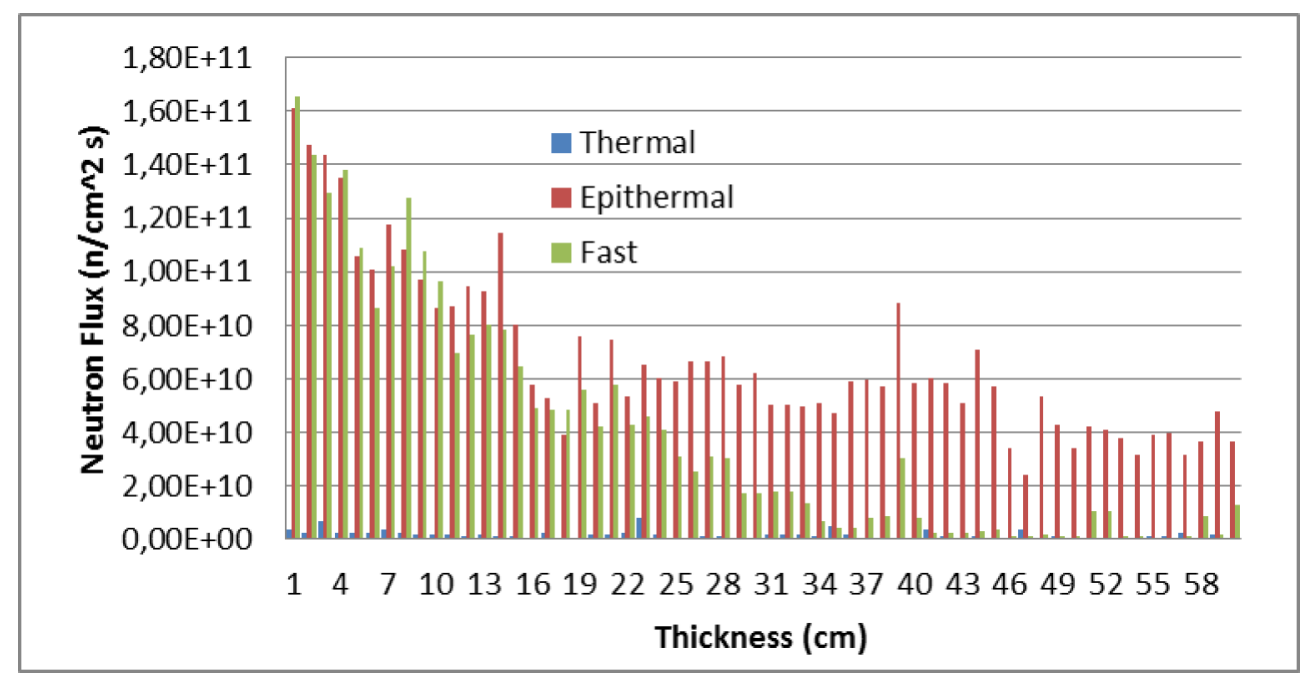

Figure 8. Neutron flux on various alumina reflector thickness

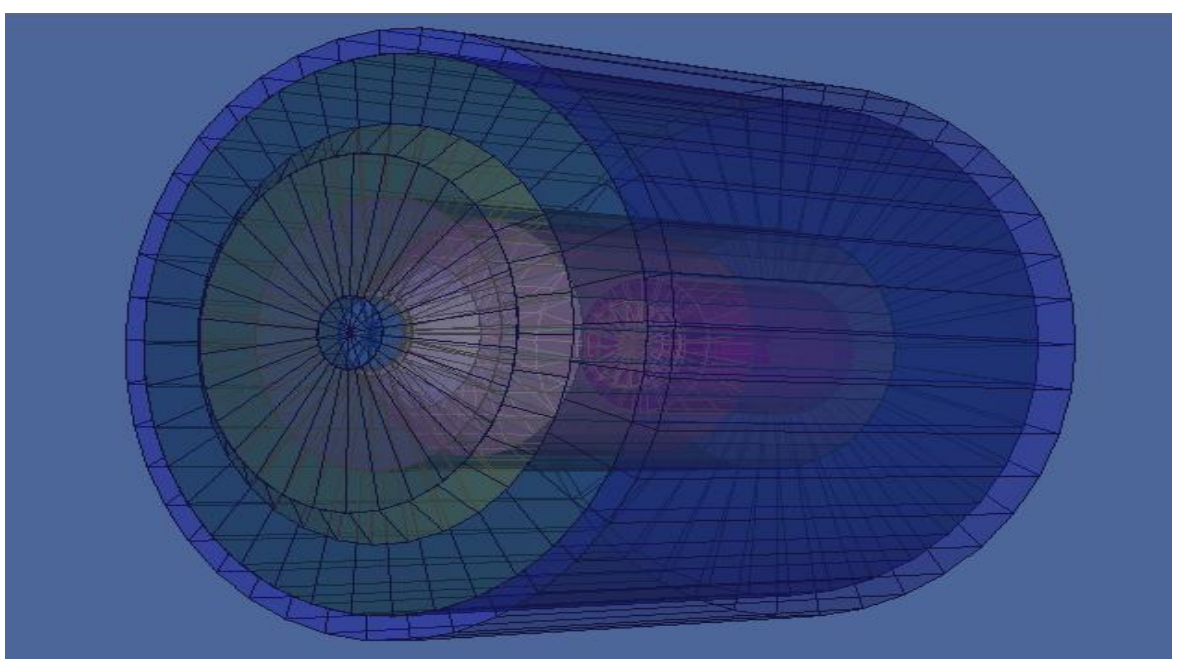

Figure 9. The Final Neutron Beam Shaping Assembly Design

Figure 8. Neutron BSA design included $35 \mathrm{~cm}$ lead as reflector, $39 \mathrm{~cm}$ alumina as moderator, $8.2 \mathrm{~cm}$ lithium fluoride as fast neutron filter and $0.5 \mathrm{~cm}$ boron carbide as thermal neutron filter. Bismuth, lead fluoride, and lead has been chosen as the aperture, reflector, and gamma shielding, respectively. The disk-type of beryllium target is $19 \mathrm{~cm}$ in diameter with $0.5 \mathrm{~cm}$ thickness that is covered by copper plate to hold the water pressured coolant.

A higher yield of neutron production requires a higher intensity of proton beams, which generate much heats and causes the target material to melt. Therefore, it is useful to consider the temperature distribution on the target material with flowing coolant by means of computer modeling to completing the target design. In this study, the ANSYS-Fluent code will be used to estimate the thermal transfer in a solid target during beam irradiation. Epithermal neutron flux in the suggested design were $1,03 \times 10^{9} \mathrm{n} / \mathrm{cm}^{2} \mathrm{~s}$, with almost all IAEA parameters for BNCT BSA design has been satisfied as shown on Table 2.

\section{CONCLUSION AND REMARKS}

A developed neutron BSA configuration has been designed. This studied was proposed to complete the last neutron collimator design which is reported by the tittle "Optimization Of 
Table 2 Neutron flux characteristics as the output of the final simulation calculation

\begin{tabular}{|c|c|c|c|}
\hline Parameters & Unit & Optimization results & IAEA standard \\
\hline Epithermal neutron flux & $\Phi_{e p i}\left(n / \mathrm{cm}^{2} \mathrm{~s}\right)$ & $1.03 \times 10^{9}$ & $>1.0 \times 10^{9}$ \\
\hline $\begin{array}{l}\text { Fast neutron dose rate to } \\
\text { epithermal neutron flux ratio }\end{array}$ & $D_{f} / \Phi_{e p i}\left(G y-c m^{2} / n\right)$ & $1.76 \mathrm{E} \times 10^{-12}$ & $<2.0 \times 10^{-13}$ \\
\hline $\begin{array}{l}\text { Gamma dose rate to epither- } \\
\text { mal neutron flux ratio }\end{array}$ & $D_{\gamma} / \Phi_{e p i}\left(G y-c m^{2} / n\right)$ & $1.19 \times 10^{-13}$ & $<2.0 \times 10^{-13}$ \\
\hline $\begin{array}{l}\text { Thermal neutron to epither- } \\
\text { mal neutron flux ratio }\end{array}$ & $\Phi_{t h} / \Phi_{e p i}$ & 0.0434 & $<0.05$ \\
\hline $\begin{array}{l}\text { Epithermal neutron current } \\
\text { to flux ratio }\end{array}$ & $J /{ }^{\Phi}{ }_{e p i}$ & 2.38 & $>0.7$ \\
\hline
\end{tabular}

Table 3. Comparison between BSA design with and without cooling system

\begin{tabular}{|c|c|c|c|}
\hline Parameters & Unit & $\begin{array}{l}\text { Using Cooling } \\
\text { System }\end{array}$ & $\begin{array}{c}\text { Without Cooling } \\
\text { System }\end{array}$ \\
\hline Epithermal neutron flux & $\Phi_{e p i}\left(\mathrm{n} / \mathrm{cm}^{2} \mathrm{~s}\right)$ & $1.03 \times 10^{9}$ & $2.0 \times 10^{y}$ \\
\hline $\begin{array}{l}\text { Fast neutron dose rate to } \\
\text { epithermal neutron flux ratio }\end{array}$ & $D_{f} / \Phi_{e p i}\left(G y-c m^{2} / n\right)$ & $1.76 \mathrm{E}_{\times 10^{-12}}$ & $9.80 \times 10^{-14}$ \\
\hline $\begin{array}{l}\text { Gamma dose rate to epither- } \\
\text { mal neutron flux ratio }\end{array}$ & $D_{\gamma} / \Phi_{e p i}\left(G y-c m^{2} / n\right)$ & $1.19 \times 10^{-16}$ & $2.53 \times 10^{-14}$ \\
\hline $\begin{array}{l}\text { Thermal neutron to epither- } \\
\text { mal neutron flux ratio }\end{array}$ & $\Phi_{t h} / \Phi_{e p i}$ & 0.0434 & 0.038 \\
\hline $\begin{array}{l}\text { Epithermal neutron current } \\
\text { to flux ratio }\end{array}$ & $J /^{\Phi_{e p i}}$ & 2,38 & 0.879 \\
\hline
\end{tabular}

Neutron Beam Shaping Assembly Design For BNCT Based Cyclotron $30 \mathrm{Mev}$ Using Monte Carlo N Particle X Code" in that those final BSA designed without target cooling system. Water pressured was proposed in this research as the coolant. The addition of cooling system design into the BSA configuration decreasing the neutron flux which is generated from the beryllium target. Table 3 shown the final results comparison between neutron BSA with and without cooling system.

The final neutron BSA design which is including the target cooling system has lower epithermal neutron flux. It is resulting the fast neutron dose rate to epithermal neutron flux higher than IAEA parameter. In spite of that parameter, almost all of other IAEA parameters for BSA design have been satisfied. This study will be continued to find out the heat transfer and thermal calculation of the beryllium target while irradiated by proton flux. Ansys-Fluent software can be used to find out the heat transfer and thermal calculation (Lee, 2011).

\section{ACKNOWLEDGMENT}

We would like to said thanks to all members who is supporting the accomplishment of the research, especially for Centre of Accelerator Science and Technology (PTSA-BATAN) for the opportunities given to perform this work.

\section{REFERENCES}

Aguino, Z.P., Vintro, X.L.Sancho, F.J., Pousa, L., dan Agusti, M.Q. (2011). Head and Neck Sarcomas . Our Experience, Acta Ottorinolaringologica Espanola, vol. 62, no. 6, 436-442.

Andoh, T., Fujimoto, T. Sudo, T., Fujita, I., Imabori, M., Moritake, H., Sugimoto, T., dan Sakuma,Y. (2011). Boron neutron capture therapy for clear cell sarcoma ( CCS ): Biodistribution study of $\mathrm{p}$-borono- 
L -phenylalanine in CCS-bearing animal models, Applied Radiation and Isotopes, vol. 69 , no. 12, 1721-1724.

Ardana, I M., Kusminarto, Sardjono,Y. (2015). Optimization Of Neutron Beam Shaping Assembly Design For Bnct Based Cyclotron 30 Mev Using Monte Carlo N Particle X Code, $1^{\text {st }}$ International Symposium: The Application of Nuclear Technology to Support National Sustainable Development for Health, Agriculture, Energy, Industry and Environment, Satya Wacana Christian University-Salatiga, Central Java

Burlon, A.A., Girola, S., Valda, A.A., Minsky, D.M., Kreiner, A.J., dan Sanchez, G., (2011). Design of a beam shaping assembly and preliminary modelling of a treatment room for accelerator-based BNCT at CNEA, vol. 69, 1688-1691.

Capoulat, M.E., Herrera, M.S., Minsky, D.M., Gonzales, S.J. dan Kreiner A.J. (2014). Be (d,n) 10 B-based neutron sources for BNCT, Applied Radiation and Isotopes, vol. 88, 190-194.

Drosg, M., Monoenergetic Neutron Production By Two-Body Reactions In The Energy Range From 0.0001 To $500 \mathrm{Mev}$, Institute Of Experimental Physics, University Of Vienna, A-1090 Wien, AUSTRIA.

Faghihi, F., dan Khalili, S. (2013). Beam Shaping Assembly of a D - T Neutron Source for BNCT and its Dosimetry Simulation in Deeply-seated Tumor, Radiation Physics and Chemistry, vol. 89, 1-13.

Hashimoto, Y., Fujio Hiraga, Yoshiaki Kiyanagi. (2014). Effects of proton energy on optimal moderator system and neutron-induced radioactivity of compact accelerator-driven $\mathrm{Be}(\mathrm{p}, \mathrm{n})$ neutron sources for BNCT, Physics Procedia, vol. 60, pp. 332-340.

Herrera, M.S. , S.J. González, D.M. Minsky, Kreiner,A.J.(2013). Evaluation of performance of an accelerator-based BNCT facility for the treatment of different tumor targets, Physica Medica, vol. 29, pp. 436-446

Imoto, M., H. Tanaka, K. Fujita, T. Mitsumoto, K. Ono, A. Maruhashi, Y. Sakurai. (2011). Evaluation for activities of component of Cyclotron-Based Epithermal Neutron Source (C-BENS) and the surface of concrete wall in irradiation room, Applied Radiation and Isotopes, Vol. 69 (2011), pp. 1646-1648.

International Atomic Energy and Agency (IAEA). (2015). Current status of neutron capture therapy, Asutria : IAEA.

Lee, B. N., J. A. Park, Y. S. Lee, H. S. Song, H. W. Kim, T. Zhou and S. H. Lee. (2011). Design of Neutron Targets with the 4 $\mathrm{MeV}$ Cyclotron for BNCT, Journal of the Korean Physical Society, Vol. 59, No. 2, pp. 2032_2034.

Mitsumoto, T., K. Fujita, T. Ogasawara, H. Tsutsui, S. Yajima, A. Maruhashi, Y. Sakurai, H. Tanaka. (2010). BNCT System Using $30 \mathrm{Mev} \mathrm{H}-$ Cyclotron, Proceedings Of Cyclotrons, Lanzhou, China

Moss, R.L. (2014). Critical review, with an optimistic outlook, on Boron Neutron Capture Therapy ( BNCT ), Applied Radiation and Isotopes, vol. 88, pp. 2-11.

Ono, Koji. (2013). Experience of BNCT by KUR and Start of Clinical BNCT Trial by Small Cyclotron Based Neutron Generator in KURRI, Ms. Power Point Presentation Slide.

Pazirandeh, A., Torkamani, A., dan Taheri, A. (2011). Design and simulation of a neutron source based on an electron linear accelerator for BNCT of skin melanoma, Applied Radiation and Isotopes, vol. 69, no. 5, 749-755.

Rasouli, F.S., Masoudi, S.F., dan Kasezas, Y., 2012, Design of a model for BSA to meet 
free beam parameters for BNCT based on multiplier system for D - T neutron source, Annals of Nuclear Energy, vol. 39, no. 1, $18-25$.

Suzuki, M., Hiroki Tanaka, Yoshinori Sakurai, Genro Kashino, Liu Yong, Shinichiro Masunaga, Yuko Kinashi, Toshinori Mitsumoto, Satoru Yajima, Hiroshi Tsutsui, Takemi Sato, Koji Ono, Akira Maruhashi. (2009). Impact of accelerator-based boron neutron capture therapy (AB-BNCT) on the treatment of multiple liver tumors and malignant pleural mesothelioma, Radiotherapy and Oncology, Vol. 9, pp. 89-95.

Tanaka, H., Sakurai, Y., Suzuki, M., Masunaga, S., Mitsumoto, T., Fujita, K., Kashino, G., Kinashi, Y., Liu, Y., Takada, M., Ono, K., dan Marushasi, A. (2011). Experimental verification of beam characteristics for cyclotron-based epithermal neutron source (C-BENS), Applied Radiation and Isotopes, vol. 69 , no. 12, 1642-1645.

Tanaka, H., Y. Sakurai, M. Suzuki, S. Masunaga, T. Mitsumoto, Y. Kinashi, M. Narabayashi, Y. Nakagawa, T. Watanabe, N. Fujimoto, A. Maruhashi, N. Kondo, K. Ono. (2014). Evaluation of thermal neutron irradiation field using a cyclotron-based neutron source for alpha autoradiography, Applied Radiation and Isotopes, vol. 88, pp. 153-156

Tanaka, K., Satoru Endo, Shunsuke Yonai, Mamoru Baba, Masaharu Hoshi. (2014). A TPD and AR based comparison of accelerator neutron irradiation fields between $\mathrm{Li}$ and $\mathrm{W}$ targets for BNCT, Applied Radiation and Isotopes, vol. 88 , pp. 229-232.

Ueda, H., Tanaka, H., Sakurai, Y. (2015). The improvement of the energy resolution in epi-thermal neutron region of Bonner sphere using boric acid water solution moderator, Applied Radiation and Isotopes, vol.104, pp. 25-28.

World Helath Organization (WHO).(2015). Cancer Key Facts, Fact Sheet, Fact sheet N²97 Updated February 2015, Article retrieved from http://www.who.int/ mediacentre/factsheets/fs297/en/

Wang, Z., Morris, C.L., Bacon J.D., Brockwell, M.I., dan Ramsey, J.C. (2014). A double helix neutron detector using micron-size 10 B powder, $L A N L$.

Yonai, S., Itoga, T., Baba, M., Nakamura, T., Yokobori, H., dan Tahara, Y. (2009) Benchmark experiments for cyclotron-based neutron source for BNCT, Applied Radiation and Isotopes, vol. 61, 997-1001. 